\title{
In vitro Antioxidant Activity in Seven Selected Local Ghanaian Spices and an Artificial Spice, Shrimp Cube
}

\author{
Bernardine Tuah $^{1, *}$, Matilda Asante ${ }^{2}$, George Asare ${ }^{3}$, Derek Doku ${ }^{3}$ \\ ${ }^{1}$ Department of Nutrition and Dietetics, University of Health and Allied Sciences, Ho, Ghana \\ ${ }^{2}$ Department of Nutrition and Dietetics, University of Ghana, Korle Bu, Ghana \\ ${ }^{3}$ Department of Chemical Pathology, University of Ghana, Korle Bu, Ghana \\ *Corresponding author: tuah.b@yahoo.com
}

\begin{abstract}
Many spices have been shown to have harmless sources of natural antioxidants and have been of great help in preventing the pathological effects caused by free radicals and their associated oxidative stress. The total antioxidant activity, total phenolic content and flavonoid content in ethanol extract of seven (7) local spices (clove, rosemary, anise seeds, calabash nutmeg, Ethiopian pepper, bayleaf and fermented African locust beans) and one artificial spice in Ghana; (shrimp cube) were determined in vitro by the 1, 1 diphenyl-2-picryl hydrazyl (DPPH) free radical scavenging assay, the Folin-Ciocalteau and aluminium chloride colorimetric methods respectively. The total phenolic content estimated for each spice decreased in the order clove $>$ rosemary $>$ bayleaf $>$ anise seeds $>$ calabash nutmeg $>$ Ethiopian pepper $>$ fermented African locust beans $>$ shrimp cube with a statistically significant p- value of 0.003 . The total flavonoid contents decreased significantly in the order clove $>$ calabash nutmeg $>$ rosemary $>$ Ethiopian pepper $>$ bayleaf $>$ anise seeds $>$ fermented African locust beans $>$ shrimp cube $(p=0.002)$. The free radical scavenging activity of the spices also decreased significantly in the order clove $>$ rosemary $>$ bayleaf $>$ anise seeds $>$ Ethiopian pepper $>$ calabash nutmeg $>$ fermented African locust $>$ shrimp cube $(\mathrm{p}=0.040)$. Statistically significant linear correlations were observed between total phenolic content and DPPH scavenging activity $(r=$ 0.976, $\mathrm{p}=0.000)$ and flavonoid content and DPPH scavenging activity $(\mathrm{r}=0.693, \mathrm{p}=0.003)$.These findings suggest that local plant-based spices are available sources of natural antioxidants than the shrimp cube. Of the seven local spices analysed, cloves had the highest antioxidant activity. Future studies should investigate the antioxidant activity of these spices in vivo.
\end{abstract}

\section{Keywords: antioxidant activity, flavonoids, local ghanaian spices, shrimp cube, phenolic content}

Cite This Article: Bernardine Tuah, Matilda Asante, George Asare, and Derek Doku, "In vitro Antioxidant Activity in Seven Selected Local Ghanaian Spices and an Artificial Spice, Shrimp Cube." World Journal of Nutrition and Health, vol. 5, no. 2 (2017): 46-52. doi: 10.12691/jnh-5-2-4.

\section{Introduction}

Spices constitute an important group of agricultural commodities which are used worldwide mostly in the culinary art. Spices could be any part of a plant that is bark, buds, fruits, leaves, roots, seeds, or the entire plant/flower [1] and are basically used in various forms, namely fresh, ripe, dried or powdered. These farm products are eaten in combination with other foods but have no caloric value. Common uses of spices are to contribute aroma, add flavour, enhance taste and in some cases add colour and visual appeal to foods. Hence, spices can be used to improve the tastiness and the appeal of foods. A survey conducted by [1] in Bangladesh found that natives used spices daily in their meals. Aside these, people use spices for various reasons. Uses of certain local spices other than food preparation included treating stomachache, toothache, earache, diarrhoea, measles, chicken pox, oedema, wounds and worm infestations [1]. In some instances spices were used to control cholesterol levels and high blood pressure.
Research has also shown that many spices contain considerable amounts of antioxidant substances that may protect cells from damages caused by unstable molecules called free radicals [2] or reactive oxygen species (ROS). These antioxidants may occur naturally in the body. ROS are toxic molecules that are released by the immune system of hosts due to inflammatory injury from immune cells such as activated neutrophils and macrophages and also during normal cellular processes such as the degradation of haemoglobin [3]. These ROS if produced in excess can overwhelm the body`s antioxidant system leading to oxidative stress [4]. Oxidative stress has been associated with diseases such as diabetes mellitus, cancer, protein energy malnutrition (PEM), cardiovascular diseases, atherosclerosis and other degenerative diseases of aging [5,6]. Antioxidants in ginger, garlic and onion according to Shobana and Naidu [7] have been found to modulate favourably the process of carcinogenesis. Turmeric and curcumin, both local Indian spices are also known to increase detoxifying enzymes, prevent damage to DNA, improve DNA repair, decrease mutation to DNA and tumour formation, and have antioxidative potentials in animals $[7,8]$. 
Currently, there is a growing interest in natural spices which appear to be important sources of natural antioxidants and in a sense regarded as nutraceuticals. In Ghana, there are a variety of local spices which have long been used for medicinal purposes as well as enhancing the taste of food. Most restaurants, canteens, fast foods joints and people from various homes add natural spices to food hence, people consciously and unconsciously consume a particular spice or different types of spices every day. Some of the spices used differ from region to region. Although most indigenous people believe these local spices have some health benefits, there is no extensive research on the antioxidant capacity of most of the local spices hence limited published information on the nutritional composition on the spices used in Ghana and their effect on health. The artificial spice, shrimp cube, is also commonly used in most home to enhance taste of food either in addition to the local spices or used solely. Recently there is increase in advertisement of the use of the artificial spice on television which with time, may cause a changing trend whereby most people will now use the (shrimp) cube, an artificial spice, for spicing their food in the absence of local spices.

Given the number of studies suggesting the health benefits in natural spices from other countries and the increasing use of the shrimp cube, there is the need to identify some local spices which are commonly used by most natives in the capital town of Ghana. Again, it is necessary to investigate the total antioxidant levels in these common local spices in Ghana and provide baseline information for these spices in relation to their total phenolic content, total flavonoid content and free radical scavenging activity. Also, to compare antioxidant activity of the local spices to the artificial spice, shrimp cube. Lastly, to determine correlation between dietary polyphenols and antioxidant activity.

\section{Materials and Methods}

\subsection{Sample Selection}

A primary survey was conducted involving 50 retailers of local spices in 2 well-known local Markets located in central Accra: Agbogbloshie market and Makola Market. The survey result was used to select seven local Ghanaian spices and the artificial spice for this study

\subsubsection{Processing of Spices}

The spices identified (Table 1) were then bought from the Agbogbloshie market in Accra. About $200 \mathrm{~g}$ of each spices bought from the market was air-dried for 2 days. The spices were then milled into fine powder using a hammer mill and stored in an air-tight container until needed.

\subsection{Regents and Solvents}

All the reagents used were of analytical grade. FolinCiocalteau, DPPH, quercetin, potassium acetate, aluminium chloride (Sigma-Aldrich, St Louis, USA), ethanol 99.7-100\% v/v (VWR BDH Prolabo), sodium carbonate anhydrous extra pure (Merck, Germany)

\subsection{Extraction}

For each milled spices, $0.05 \mathrm{~g}$ was weighed into $15 \mathrm{ml}$ falcon tubes and $10 \mathrm{ml}$ of $60 \%$ ethanol was added. This was vortexed continuously for two minutes and allowed to stand for 5 minutes. The supernatant portion of each spice was then decanted into another tube. Ten (10) $\mathrm{ml}$ of $60 \%$ ethanol was added again to the spices and the above process repeated. Afterwards, $5 \mathrm{ml}$ of the $60 \%$ ethanol was added to each sample, vortexed for another two minutes and stored overnight in a freezer. The supernatants of the spices were decanted into the same tubes making a total volume of $25 \mathrm{ml}$ extracts. The extracts obtained for each spice was used for spectrophotometric measurements.

\subsection{Determination of Total Phenolic Content}

The Folin-Ciocalteau method was used to determine total phenolic contents in the spices [9].

To $3 \mathrm{ml}$ of distilled water, $50 \mu \mathrm{l}$ of each sample was added. Then $250 \mu \mathrm{l}$ freshly prepared Folin-Ciocalteau reagent was added followed by $750 \mu$ l of $20 \%$ (w/v) sodium carbonate solution. The samples were then incubated for 30 minutes in the dark and the absorbance read at $760 \mathrm{~nm}$ using a UV-VIS Shimadzu Corporation 1201 spectrophotometer (Kyoto, Japan). The absorbance for each local spice and standard were performed in triplicates. The total phenolic content of the spices were expressed in mg gallic acid equivalent (mgGAE)/g sample. A calibration linear regression equation of $y=1.1303 x+$ 0.0046 with $\mathrm{R}^{2}=0.9950$ obtained from the calibration curve

\subsection{Determination of Total Flavonoid Content}

The total flavonoid content in each spice was determined using the aluminium chloride method of $[10,11]$.

Table 1. List of Spices identified from survey and used for analysed

\begin{tabular}{|l|l|l|}
\hline Spices & local name & specis \\
\hline Clove & pepre & Eugenia caryophyllis/syzygium aromaticum \\
\hline Rosemary & N/A & Rosmarinus officinalis \\
\hline Bayleaf & N/A & Laurus nobili \\
\hline Anise seed & nkitinkiti & Pimpinella anisum \\
\hline Ethiopian pepper & hwentia & Xylopia aethiopica \\
\hline Fermented African locust beans & dawadawa & Parkia biglobosa \\
\hline Shrimp cube & Mounkor cube & N/A \\
\hline
\end{tabular}


The following were added to a test tube: $2.8 \mathrm{ml}$ of distilled water, $500 \mu \mathrm{l}$ of sample extract, $1.5 \mathrm{ml}$ of ethanol $(99.7-100 \% \mathrm{v} / \mathrm{v}), 100 \mu \mathrm{l}$ of $1 \mathrm{M}$ potassium acetate and 100 $\mu \mathrm{l}$ of $10 \%(\mathrm{w} / \mathrm{v})$ aluminium chloride. The samples were then incubated for 30 minutes in the dark and the absorbance read at $415 \mathrm{~nm}$. The absorbance were performed in triplicates. Flavonoid content of the spices were estimated quantitatively and expressed in $\mathrm{mg}$ of quercetin equivalent (mgQE)/g sample.

A calibration linear regression equation of $y=0.0062 x$ +0.0047 with $\mathrm{R}^{2}=0.9992$ was obtained from the calibration curve.

\subsection{Determination of Total Antioxidant Activity (TAA)}

The TAA in the spices was determined using the DPPH radical scavenging method of [11,12]. DPPH solution of concentration $0.004 \%(\mathrm{w} / \mathrm{v})$ was prepared and $200 \mu \mathrm{l}$ of each sample extract was added to $3.8 \mathrm{ml}$ of $0.004 \% \mathrm{DPPH}$ to make a total volume of $4 \mathrm{ml}$. The samples were then incubated for 30 minutes in the dark. The scavenging reducing ability of DPPH radical was determined by the decrease in its absorbance by samples and standards at $517 \mathrm{~nm}$. Readings were done in duplicates.

The ability of the spices to scavenge DPPH radical referred to as inhibition was determined with the equation.

$$
\% \text { inhibition }=\frac{A_{\mathrm{DPPH}}-\mathrm{A}_{\text {Sample }}}{\mathrm{A}_{\mathrm{DPPH}}} \times 100
$$

$\mathrm{A}_{\mathrm{DPPH}}=$ absorbance of $0.004 \% \mathrm{DPPH}$

$\mathrm{A}_{\text {sample }}=$ absorbance of samples.

\subsection{Data Analysis}

SPSS version 20.0 was used to perform statistical analysis of data. Statistical analysis was performed using Kruskal-Wallis one way analysis of variance. A post hoc analysis using Bonferroni was conducted to determine where differences occurred within the group. A $P$ value of $<0.05$ was considered statistically significant and means were expressed as mean \pm SEM. Spearman rho test was used to determine correlation between variance measured. Correlation was significant at 0.01 level (2 -tailed)

\section{Results}

The total phenolic content, total flavonoid content and total antioxidant activity in the spices are reported as the mean concentration of each spices as $\mathrm{mg} \mathrm{GAE/g,} \mathrm{mg} \mathrm{QE/g}$ and percentage (Figure 1 - Figure 3) respectively. Multiple comparisons of local spices with artificial spice for total phenolic, total flavonoids and total antioxidant activity was done and shown in Table 2. Correlation between total antioxidant activity and the polyphenols also presented in Table 3. The main ingredients in the shrimp cube based on food labelling were mono sodium glutamate, iodine, sodium inosinate and sodium guanylate, starch and modified starch, sugar, vegetable oil, shrimp maltodextrin, fish, ferric pyrophosphate and spices and spices extract

\subsection{Total Phenolic Content}

All the spices analysed were found to contain varying concentrations of phenolics in the ethanol extract. Clove, rosemary and bayleaf had the high total phenolic content (952.30 mgGAE/g, $133.45 \mathrm{mgGAE} / \mathrm{g}$ and 128.62mgGAE/g respectively). The artificial spice, shrimp cube had the lowest total phenolic content of $0.68 \mathrm{mgGAE} / \mathrm{g}$ (Figure 1 ) among all the spices.

\subsection{Total Flavonoid Content}

Clove, calabash nutmeg and rosemary had high total flavonoid content (125.48 mgQE/g, 40.25mgQE/g and $26.57 \mathrm{mgQE} / \mathrm{g}$ respectively). The artificial spice, shrimp cube had no detectable flavonoid in the ethanol extract (Figure 2).

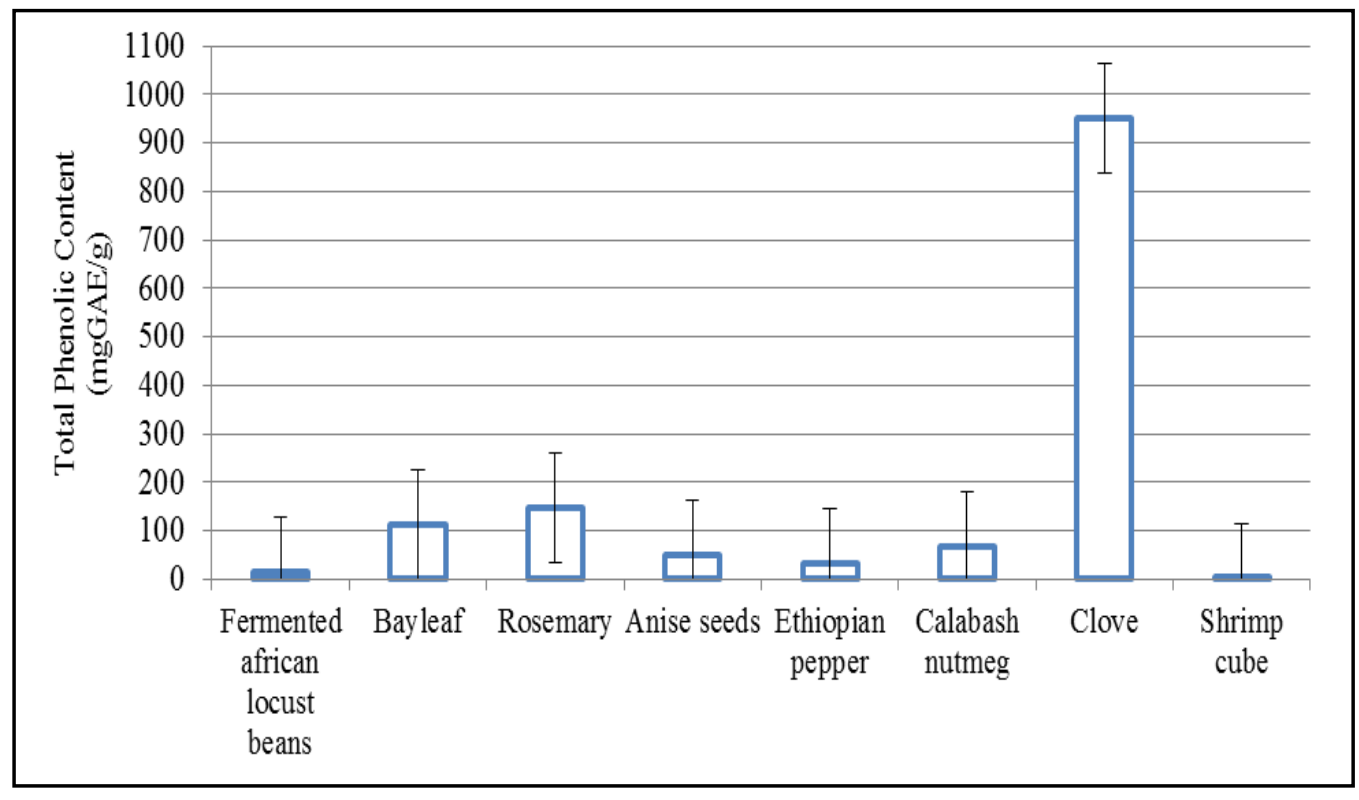

Figure 1. Concentration of total phenolic contents in the spices expressed as mg GAE/g spice. $(\mathrm{p}$-value $=0.003)$ 


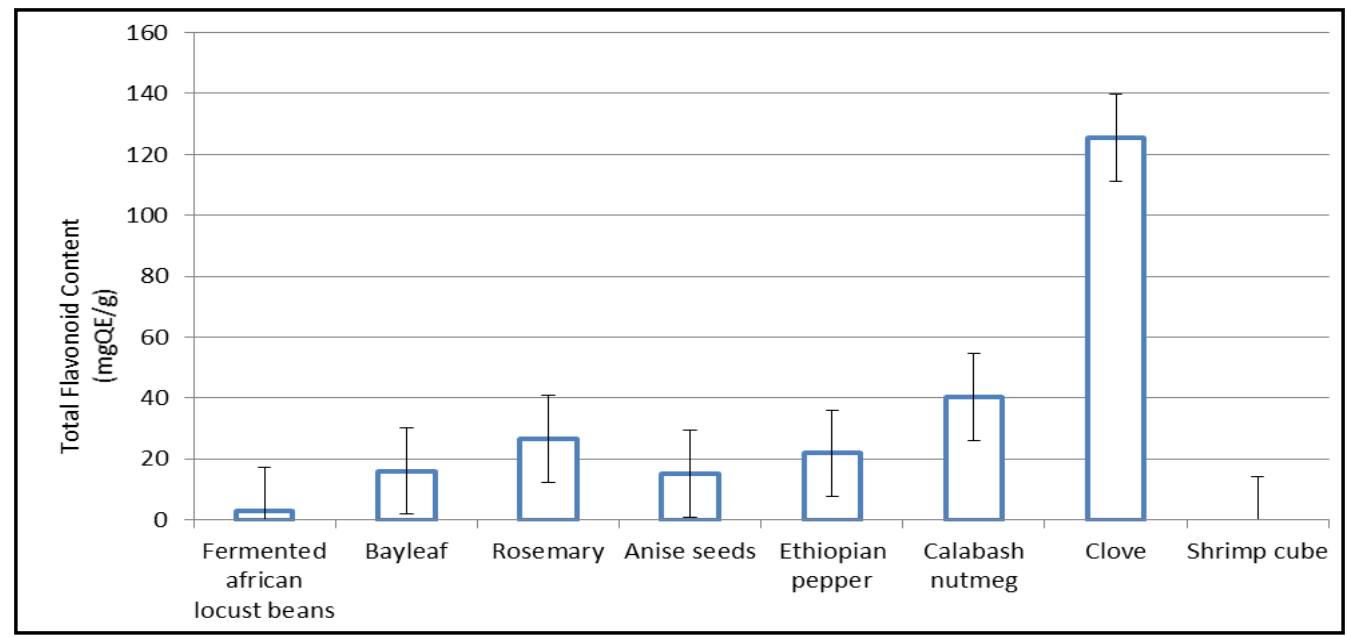

Figure 2. Concentration of total flavonoid contents in the spices expressed as mgQE/g. (p-value=0.002)

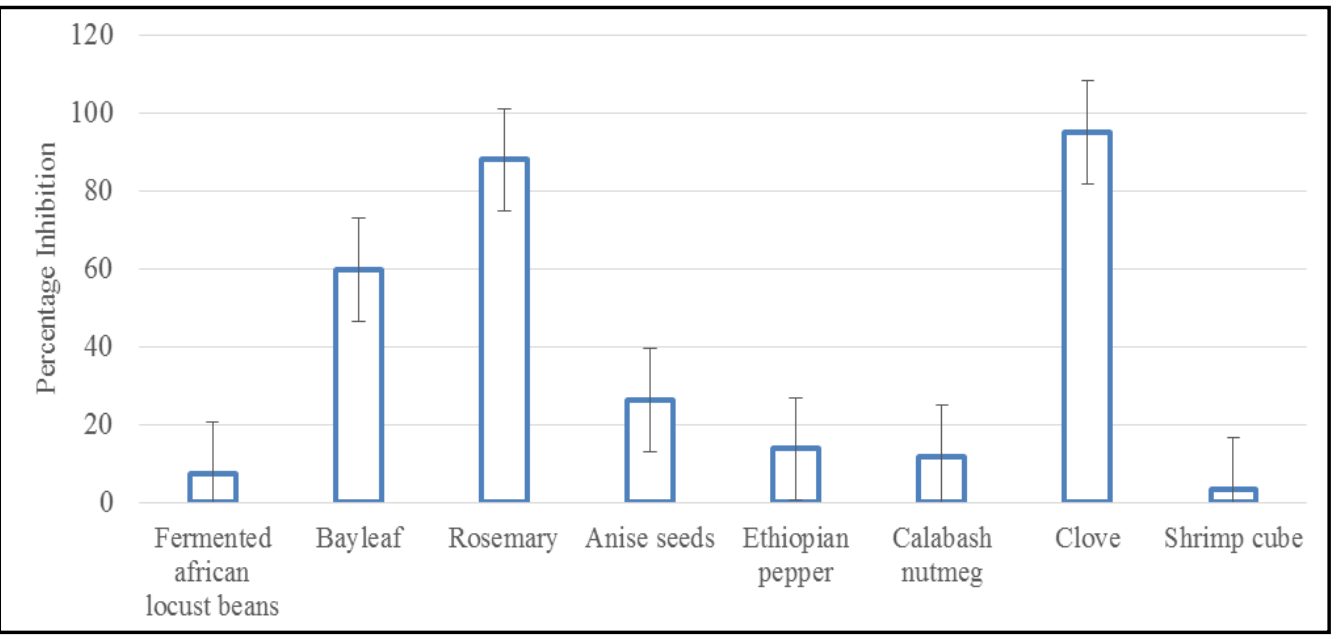

Figure 3. The percentage inhibition of the DPPH radical by the spices $(\mathrm{P}$-value $=0.040)$

Table 2. P- values by Comparison between Shrimp Cube with the Seven Local Ghanaian Spices

\begin{tabular}{llccc}
\hline & Total Phenolic & Total Flavonoid & $\begin{array}{c}\text { DPPH radical } \\
\text { Content }\end{array}$ & $\begin{array}{c}\text { Content } \\
\text { Scavenging Activity }\end{array}$ \\
\hline Spices & Fermented African locust beans & p-value & p- value & p-value \\
Shrimp cube & Bayleaf & 1.000 & $\mathbf{0 . 0 0 0}$ & 1.000 \\
& Rosemary & $\mathbf{0 . 0 0 0}$ & $\mathbf{0 . 0 0 0}$ & $\mathbf{0 . 0 0 0}$ \\
& Anise seeds & $\mathbf{0 . 0 0 0}$ & $\mathbf{0 . 0 0 0}$ & $\mathbf{0 . 0 0 0}$ \\
& African pepper & 0.217 & $\mathbf{0 . 0 0 0}$ & $\mathbf{0 . 0 0 1}$ \\
& Calabash nutmeg & 0.826 & $\mathbf{0 . 0 0 0}$ & 0.161 \\
& Clove & 0.272 & $\mathbf{0 . 0 0 0}$ & 0.438 \\
\end{tabular}

\subsection{Total Antioxidant Activity}

Clove, rosemary and bayleaf had high scavenging activity (95.0 \% 88\% and $60 \%$ respectively). Shrimp cube had the lowest scavenging activity of $2.9 \%$ (Figure 3 ). Gallic acid was used as standard and had a percentage inhibition of 95.6.

\subsection{Comparisons of local Ghanaian Spices with Artificial Spice}

Clove, bayleaf and rosemary showed high phenol contents which significantly higher than phenolic content in the shrimp cube. Since there was no flavonoid in the artificial shrimp cube all local spices had significantly higher flavonoid content compared to this artificial spice. For the DPPH assay, clove, bayleaf, rosemary and anise seeds displayed significantly higher scavenging activity compared to shrimp cube (Table 2).

\subsection{Association between Antioxidant Scavenging Activity Dietary Polyphenol Contents of Spices}

There was a strong association between the DPPH scavenging activity and the total phenolic contents. There was also a moderate association between the DPPH scavenging activity and flavonoid contents (Table 2). 
Table 3. Correlation between Antioxidant Scavenging Activity and Dietary Polyphenols Contents of Spices

\begin{tabular}{|c|c|c|}
\hline & $\begin{array}{c}\text { Total phenolic } \\
\text { content }\end{array}$ & $\begin{array}{c}\text { Total Flavonoid } \\
\text { Content }\end{array}$ \\
\hline $\begin{array}{c}\text { \% Inhibition } \\
\text { Correlation Coefficient }\end{array}$ & $0.976^{* *}$ & $0.693^{* *}$ \\
\hline Sig. (2-tailed) & 0.000 & 0.003 \\
\hline
\end{tabular}

**Correlation is significant at the 0.01 level (2-tailed).

\section{Discussion}

Phenolic compounds are phytochemicals in foods that have been found to possess antioxidant activity. The values obtained in this study for the total phenolic content were higher for some of the local spices compared to values reported by some studies [13,14,15,16,17].

Tavassoli and djomeh [13] assessed the total phenolic of methanol extracts of rosemary and estimated the total phenolic content of $49.9 \mathrm{mg}$ GAE /g of herb with Shan et al. [14] estimating $50.5 \mathrm{mg}$ GAE /g. Likewise Shan et al. [14] found the total phenolic content of the methanol extract of bayleaf and cloves to be $41.7 \mathrm{mg} \mathrm{GAE} / \mathrm{g}$ and $413.8 \mathrm{mg}$ GAE /g respectively. Although clove had the highest phenolic content among the three spices (clove, rosemary, bayleaf) in their study the values for the spices were lower than the estimated total phenolic content of the ethanolic rosemary, clove and bayleaf extracts in this study. Bamdad et al. [15] also, estimated total phenolic content of methanolic clove extract to be $243.91 \mathrm{mg}$ tannic acid equivalent/g which was lower compared to value obtained for clove in this study. Thus it may be inferred that ethanolic extraction gives a higher yield of total phenolics in rosemary compared to methanolic extraction. Kim et al. [16] also found hot water extract of clove to have the highest phenolic content (108.28 $\mu \mathrm{g}$ catelin/g) among 13 spices. This confirms that cloves are high in phenolic content regardless of the solvent used for extraction. Lamien-Meda et al. [17] found fermented African locust beans to have total phenolic contents of $3.81 \mathrm{mg} \mathrm{GAE} / \mathrm{g}$ and $5.26 \mathrm{mg}$ GAE/g in methanol and acetone extracts, respectively, which were also lower than values reported for the ethanol extract in this study.

According to James et al. [18], the kind of solvent used in extraction influences the degree and amount of phenolic compounds extracted. In phenolic extract of plants, there is always the presence a mixture of different classes of phenols which are solely dependent on their solubility in a particular solvent. The use of ethanol solution gives a satisfactory result for the extraction process for most of the plant species [19]. The phenolic content of clove, rosemary, bayleaf, anise seeds, calabash nutmeg and African pepper in this study were found to be higher than that found in the vegetable, dandelion [20,21].

Kim et al. [16] reported an estimated value of total flavonoid contents in clove to be $75.97 \mathrm{mg} \mathrm{QE} / \mathrm{g}$ and that for rosemary to be $299.84 \mathrm{mg} \mathrm{QE} / \mathrm{g}$ for which hot water was used as the extraction solvent. This contrasted findings in this study whereby cloves had the highest flavonoid content of $125.48 \mathrm{mg} \mathrm{QE} / \mathrm{g}$ and rosemary had $26.57 \mathrm{mg}$ QE/g. This could suggest that hot water is capable of extracting more flavonoids from rosemary. For clove, hot water extraction might not be a good extraction solvent compared to ethanol hence accounting for the difference in the flavonoid content. The estimated total flavonoid content of calabash nutmeg was found to be higher than values reported by Ogunmoyale et al. [22] for both the ethanolic and aqueous extracts. From this study, calabash nutmeg had more abundant flavonoid content than its total phenolic contents and its total flavonoid content was the second highest among the spices. Lamien-Meda et al. [17] found no detectable flavonoids in methanol and acetone extract of fermented African locust beans and similarly among the local spices analysed in this study, fermented African locust beans had the lowest flavonoid content. Thus could be attributed to the fact that methanol and acetone solvents were incapable of extracting Flavonoids from this spice compared to ethanol. Geographical locations of growth of spices and seasonal variations may also implicate invariability of amounts of total phenolic and total flavonoid compounds in the spices.

Flavonoids and phenolic acids are the main groups of phenolic compounds with phenolic acids making up onethird of the total intake while the remaining two-thirds is accounted for by flavonoids which consist of several subclasses such as flavanols (being the most abundant flavonoids in diet), flavanones, flavonols, isoflavones and anthocyanidins [23,24]. The aluminium chloride method for determining total flavonoid contents in plants/food is specific to flavonols and flavones due to their stability with aluminium chloride [25]. There is no single colorimetric assay that is capable of detecting all flavonoids in a plant/food [25], thus, the low total flavonoid contents obtained for the spices as compared to the total phenolic contents in this study could probably be due to underestimation of the total flavonoid content of the spices.

Kim et al. [16] found the percentage inhibition of hot water extract of clove to be $84.22 \%$ and that of rosemary to be 56.98\%. Among the spices Kim et al. [16] assessed, clove had the highest scavenging activity which agreed with findings in this study (95\%) despite the low flavonoid content they reported for clove. This could imply that the antioxidant activity was responsible by the total phenolic content. The percent inhibition of DPPH by rosemary ethanolic extract in the study by Santos et al. [26] was $90.14 \%$ which was again marginally higher than the inhibition percentage (88\%) obtained in this study. This discrepancy could be attributed to the difference in concentration of phenolics in the ethanolic extract for rosemary. However, since the concentration obtained (0.46 $\mathrm{mg}$ GAE/ml of extract) by Santos et al. [26] was about 3.5 times higher than the observed concentration ( $0.13 \mathrm{mg} \mathrm{GAE} / \mathrm{ml}$ of extract) in this study, it was expected that the percentage inhibition would have followed the same trend. This expectation was on the contrary not observed. It may be deduced that a critical concentration of phenolics in a sample is adequate to attain a preferred antioxidant activity after which there might be a saturation effect, nullifying any increase in the antioxidant activity by the presence of additional phenolics in the sample [26]. Considering the amount of total phenolic content, total flavonoid content obtained for the various spices and the trend observed for their antioxidant activity, it could be deduced that in contributing to the antioxidant activity, the physico-chemical nature and the chemical structures of the 
individual phenolics in the extracts may be more important than the total phenolic content $[27,28]$ and the antioxidant activity could also be due to a synergistic effect by both phenolic and flavonoid contents in the spices. Also, since a phenolic extract contains a mixture of phenols, it implies that the various phenolic compounds may respond differently in DPPH depending on the amount of phenolic groups they possess [29].

Clove, bayleaf and rosemary showed high total phenolic contents which were significantly higher than the total phenolic content in shrimp cube. Since there was no detectable flavonoid in the shrimp cube, all the local spices had significantly higher total flavonoid content compared to the shrimp cube. For the DPPH assay, clove, bayleaf, rosemary and anise seeds displayed significantly higher scavenging activity compared to the artificial spice.

Studies have shown polyphenols have a relationship with the antioxidant activity of many plants [16,30]. In a study involving five varieties of Philippine sweet potatoes, Rumbaoa et al. [30] reported a negative correlation between total phenolic content and DPPH scavenging activity $(r=-0.826)$ indicating that antioxidant activity decreases with increasing total phenolic content. However, similar to findings by Kim et al. [16], a significant relationship existed between total phenolic contents and $\mathrm{DPPH}$ scavenging activity in this study $(\mathrm{r}=0.976$, $\mathrm{p}=0.000$ ). A significant relationship was found for flavonoid and DPPH scavenging activity as well ( $r=0.693$, $\mathrm{p}=0.003$ ) in this study. This association between flavonoid content and DPPH scavenging activity somehow agreed with results obtained by Kim et al. [16] however according to Kim et al. [16] the association between flavonoid content and DPPH scavenging activity was statistically not significant. The relationship between the antioxidant characteristics and DPPH scavenging activity imply that the antioxidant activity of the spices is mostly dependent on the total phenolic content even though flavonoids are more abundant in foods compared to phenolics.

\section{Conclusion}

The local Ghanaian plant-base spices are available sources of natural antioxidants than the shrimp cube. The low amount of total phenolic content in the shrimp cube, no detectable amount of total flavonoids and the low percentage free radical scavenging activity raises concern about the rapid changing trend in our cooking practices. Although the body produces its own antioxidants, consumption of antioxidant rich foods is believed to provide protective benefits against oxidative stress caused by these diseases. A lot of local Ghanaian spices are used daily, however there is minimum evidence concerning the antioxidant capacity and activity in these spices. Most people think natural antioxidants are obtained strictly from foods such as fruits and vegetables which may not be consumed daily. These Ghanaian local spices may have different antioxidant properties which may be useful in reducing disease risk.

This study also serves as a baseline study for further work to be done. This will help provide food industries with evidence-based information that may guide them in developing functional foods and nutraceuticals. Also further studies on these local spices would provide enough evidence to justify increase use of these spices and advocate for their domestication to consumers and the general population. Future studies should investigate the antioxidant activity of these spices in vivo.

\section{Conflict of Interest}

There is no conflict of interest to be disclosed.

\section{Acknowledgements}

I wish to thank all members of the Applied Radiation Biology Centre, Ghana Atomic Energy commission (GAEC) for their help and co-operation

\section{References}

[1] Takeda J., Desilva S., Muthuraman P., Rahman S.M., and Kawet l. Spices in Sri Lanka, India and Bangladesh with special reference to the usages and consumption. Bull. Fac. Agric. Saga Univ., 93: 1-25, 2008.

[2] Tempest M. Adding spice a healthy life- Evidence shows antioxidants rich herbs and spices may cut chronic disease risk. Today`s Dietitian, 14(3): 40, 2012.

[3] Conforti F., Sosa S., Marrelli M., Menichini F., Statti G.A., Uzunov D., Tubaro A., Menichini F., Loggia R.D. In vivo antiinflammmary and in vitro antioxidant level activities of Mediterranean dietary plants. J. Ethnopharmacol., 116:144-151, 2007.

[4] Kulkarni A.G., Suryakar A.N., Sardeshmukh A.S., Rathi D.B. Studies on biochemical changes with special reference to oxidant and antioxidant in malaria patients. Ind. J. Clin. Biochem, 18(2): 136-40, 2003

[5] Aruoma O.I. Free radicals, oxidative stress and antioxidants in human health and disease. J. Am. Oil Chem. Soc., 75:199-212, 1998.

[6] Omoregie E.S. and Osagie A.U. Effect of Jatropha tanjorensis leaves supplement on the activities of some antioxidant enzymes, vitamins and lipid peroxidation in rats. J. Food Biochem, 35(2): 409-424, 2011.

[7] Shobana S. and Naidu K.A. Antioxidant activity of selected Indian spices. Prostagladins Leukot. Essent. Fatty acid, 62(2): 107-110, 2000.

[8] Krishnaswamy K. Traditional Indian spices and their health. Asian Pac. J. Clin. Nutr, 17(1): 265-268, 2008.

[9] Singleton V.L., Orthofer R., Lamuela-Raventos R.M. Analysis of total phenols and other oxidative substrates and antioxidants by means of Folin-Ciocalteau reagent. Methods Enzymol., 299: 152178, 1999.

[10] Zhishen J., Mengcheng T., Jianming W. The determination of flavonoid content in mulberry and their scavenging effects on superoxide radicals. Food Chem., 64: 555-559, 1999.

[11] Ahiakpa J.K., Quartey E.K., Amoatey H.M., Klu G.Y.P., Achel D.G, Achoribo E and Agbenyegah S. Total flavonoids, phenolic contents and antioxidant scavenging activity in 25 accessions of okra (Abelmoschus spp L.) Afr. J. Food Sci. Tech., 4(5): 129-135, 2013.

[12] Blois M.S. Antioxidant determinations by the use of a stable free radical. Nature, 181: 1199-1200, 1958.

[13] Tavassoli S. and Djomeh Z.E. Total phenols, antioxidant potential and antimicrobial activity of methanol extract of rosemary (Rosmarinus officinalis L.). Global Veterinaria, 7(4): 337-341, 2011.

[14] Shan B., Cai Y.Z., Sun M., Corke H.Antioxidant capacity of 26 spice extracts and characterization of their phenolic constituent. $J$. Agric. Food Chem., 53(20): 7749-7759, 2005. 
[15] Bamdad F., Kadivar M., Keramat J. Evaluation of phenolic and antioxidant activity of Iranian caraway in comparison with clove and BHT using model systems and vegetable oil. Int. J. Food Sci. Tech., 14(s1): 20-27, 2006.

[16] Kim I.S., Yang M.R., Lee O.H, Kang S.H. Antioxidant activities of hot water extracts from various spices. Int. J. Mol. Sci., 12(6): 4120-4131, 2011.

[17] Lamien-Meda A., Lamien C.E., Compaore M.M.Y., Meda R.N.T., Kiendrebeogo M., Zeba B., Millogo J.F., Nacoulma O.G. Polyphenols content and antioxidant activity of fourteen wild edible fruits from Burkina Faso. Molecules, 13: 581-594, 2008.

[18] James D.B., Sheneni V.D., Kadejo O.A., Yatai K.B. Phytochemical screening and in vitro antioxidant in different solvent extracts of Vitex doniana leaves, stem bar and root bark. Am. J. Biomed. Life Sci., 2(1): 22-27, 2014.

[19] Zohra M. Impact of solvent extraction type on total polyphenols content and biological activity from Tamarix aphylla (L). Int. J. Pharm. Biol., 2(1): 609-615, 2011

[20] Ghaima K.K., Hashim N.M., Ali S.A. Antibacterial and antioxidant activities of ethyl acetate extract of nettle (Urtica dioica) and dandelion (Taraxacum officinale). J. Appl. Pharm. Sci., 3(05): 096-099, 2013.

[21] Özcan M.M., Paksoy M., Ünver A. The antioxidant capacity and total phenol contents of leaves and roots of Taraxacum officinale. J. Agroali. Pro. Tech., 18(4): 270-271, 2012.

[22] Ogunmoyale T., Inaboya S., Makun J.O., Kade I.J. Differential antioxidant properties of ethanol and water soluble phytochemicals of false nutmeg (Monodora myristica) seeds. Int. J. Biochem. Biotech, 2(1): 253-262, 2013.

[23] Han X., Shen T., Lou H. Dietary polyphenols and their biological significance. Int. J. Mol. Sci., 8(9):950-988, 2007

[24] Manach C., Williamson G., Morand C., Scalbert A., Remesy C. Bioavailability and bio-efficacy of polyphenols in human. 1 review of 97 bioavalability studies. Am. J. Clin. Nutr. 81(1 suppl): 230S-242S, 2005.

[25] Chang C.C., Yang M.H., Wen H.M., Chern J.C. Estimation of total flavonoid content in propolis by complementary colorimetric methods. J. Food Drug Anal., 10: 178-182, 2002.

[26] Santos R.D., Shetty K., Cecchini A.L., da Silva Miglioranza L.H. Phenolic compounds and total antioxidant activity determination in rosemary and oregano extracts and its use in cheese spread. Ciências Agrárias, 33(2): 655-666, 2012.

[27] Li W.J., Cheng X.L., Liu J., Rui C.L., Wang G.L., Du S.S., Liu Z.L. Phenolic compounds and antioxidant activities of Liriope muscari. Molecules, 17(2): 797-1808, 2012.

[28] Rodríguez-Rojo S., Visentin A., Maestri D., Cocero M. J. Assisted extraction of rosemary antioxidants with green solvents. $J$. Food Eng., 109(1): 98-103, 2012.

[29] Anokwuru P.C., Esiaba I., Ajibaye O., Adesuji A.O. Polyphenolic content and antioxidant activity of Hibiscus sabdariffa calyx. Res. J. Med. Plant, 5: 557-566, 2011.

[30] Rumbaoa R.G.O., Cornago D.F., Geronimo I.M. Phenolic content and antioxidant of Philippine sweet potato (Ipomoea batatas) varieties. Food Chem., 113: 1133-1138, 2009. 